\title{
China Aviation Oil and JETBLUE AIRWAYS
}

\author{
Yishu Shi * \\ Jinhua Vocational and Technical College, Jinhua, Zhejiang 321000 ,China.
}

Abstract:China Aviation Oil had to ask for help from the group for the first on October 10, 2004 due to it was unable to operate the subsidiary with huge losses. On December 1st, 2004, after a massive loss of \$550 million U.S. dollars, CAO announced an application for bankruptcy protection in court.

Keywords:China Aviation Oil;Risk;Techniques;Fuel Hedging;JetBlue Airways;Management

\section{China Aviation Oil (2004)}

\subsection{Facts and Backgrounds}

CAO's full name is China National Aviation Fuel Corporation which is a large Chinese government-owned air transportation service guarantee enterprise. It is an integrated aviation fuel supplier with main businesses including aviation fuel procurement, transportation, storage, testing, sales, refuelling. Its core business is to construct fuel supply facilities and purchase fuelling devices for more than 100 airfields across China; providing fuelling services for more than 100 domestic and foreign airlines. It is established in 1993. And its headquarters and registration place are located in Singapore. It is an overseas holding subsidiary of China Aviation Oil Group. It was listed on the Singapore Exchange's main board in 2001, which become the first Chinese government-funded company listed abroad through using its overseas assets.

In April 2003, China Aviation Oil Corporation became the second batch of country-owned enterprises eligible for overseas futures trading, which was approved by the Chinese regulators (Arnold, 2005). CAO has been conducting hedging businesses of oil futures since 2003. During this period, CAO expanded its own business scope without authorization and participated in extremely risky oil options trading.

Dickie (2004) stated CAO had to ask for help from the group for the first on October 10, 2004 due to it was unable to operate the subsidiary with huge losses. Its report included $\$ 180$ million paper loss and serious cash flow problems, \$26 million in working capital used up, \$120 million syndicated loans, and \$68 million account receivables. On December 1st, 2004, after a massive loss of \$550 million U.S. dollars, CAO announced an application for bankruptcy protection in court.

\subsection{CAO's Risks and RM Techniques}

1.2.1 CAO's Risks

There are 4 kinds of risk CAO had in this issue: a lack of risk management culture within the company, a lack of understanding of the risks of financial derivatives business, failure to effectively implement the risk limit management system and internal control \& supervision mechanism.

Since October 2003, CAO predicted a decline in oil prices. Therefore, the company changed its option trading strategy. Arnold (2005) pointed It shorted lots of oil call options and longed put options, which attempted to continue to profit through hedging. However, it misjudged the tendency of oil prices. Since 2004 (October 2003 to April 2004), international oil prices have soared from $\$ 26$ to $\$ 33$ per barrel nearly because of various factors, and the company's losses have continued to expand (Prystay, 2005). When the options were settled in April 2004, the oil price had soared to \$38 per barrel, and CAO occurred a loss of $\$ 5.8$ million.

At this time, CAO did not withdraw from the market, but chose an aggressive speculative strategy-shifting. The specific strategy was to buy the previously sold call options and liquidate them while not executing the previously purchased put options. At the same time, the company chose to sell more call options with higher strike prices and utilized the premiums to make up the margin gap (Arnold, 2005). From April 2004 to October 2004, CAO successively sold numerous oil call options. The effective contract volume totalled 52 million barrels, and CAO's annual import volume was around 15 million barrels (exceeded 3 times CAO's annual usage) (Arnold, 2005). In June 2004, the company received the first margin call. In the third quarter of 2004, the company repeated its previous strategy three times, the book loss of CAO Options continued to increase by geometric multiples as oil's prices soared from $\$ 30$ to $\$ 50$ per barrel during the period. On December 1st, 2004, it lost $\$ 550$ million at all.

\section{Copyright (C) 2020 Yishu Shi}

doi: 10.18282/1-e.v9i4.1678

This is an open-access article distributed under the terms of the Creative Commons Attribution Non-Commercial License (http://creativecommons.org/licenses/by-nc/4.0/), which permits unrestricted non-commercial use, distribution, and reproduction in any medium, provided the original work is properly cited. 
1.2.2 RM Techniques

Firstly, CAO also used short calls with long puts for earning more money with different strike prices, which liked 'collar' without owning real assets. However, it was meaningless for protecting themselves with this derivative strategy. Secondly, CAO used some systems for avoid high risk activities. Mure (2004) stated Ernst \& Young compiled the "Risk Management Manual" for $\mathrm{CAO}$ with a 7 people risk management committee and software monitoring system. In the manual, the situation would be reported and cross-controlled by board of directors, traders, risk control committee, president, audit department. Especially, for the losses, each trader needed to report to the risk control committee and asked for opinions when losing $\$ 200,000$; it is necessary to report and asked for the president's opinions when losing $\$ 350,000$, which determined whether continue or not; finally, any transaction caused a loss of more than $\$ 500,000$ will be automatically closed (Mure, 2004).

\subsection{Explanations}

There are 2 main reasons for this issue with considerations of RM. Firstly, CAO's internal RM environment played a big role. The management often relied on the outstanding performance in the past to guide decision-making, and the attitude towards risk control is usually based on the management's subjective judgments. In this issue, Chen Jiulin still trusted the oil prices would drop after rising. This fact indicated CAO's extreme risk appetite and abnormal risk culture. Secondly, CAO had serious problems in the function's division. The president, Chen Jiulin, ignored company regulations. And he even had the functions of inspection, authorization, supervision, and execution at the same time without any obstacles (no reports), which was against with "Risk Management Manual" totally. Thirdly, it did not execute internal control \& supervision mechanism. There are 10 traders in CAO at that moment, so the total loss should be limited in $\$ 5$ million $(500,000 * 10)$. However, after $\$ 5.8$ million lost on the book value, Chen Jiulin did not report any thing to the Group. And he chose another aggressive and extremely risky option strategy (shifting) continuously for recovering losses.

\subsection{RM Performance Evaluation and Suggestions}

CAO's RM performance's Implementation and supervision were not good although it had complete risk management system with many different departments. There was meaningless for the group to use this mechanism to control the risk at all. If other people in the management knew shorted oil calls was too dangerous due to it was the riskiest way in trading options, this issue would be argued with Chen Jiulin. And CAO might not loss such a huge amount of capitals even after losing \$5.8 million.

The main problem is risk monitoring \& control which is the final step in all 6 steps in CRM. So, the group should resend its own employees or third party for doing meaningful activities (Oversee, audit, tune and re-align the RM process). Secondly, shorting calls is too risky for trading because the potential losses are unlimited, but the benefits are limited. So, if CAO really wanted to trade options, they need more appropriate strategies like 'collar' (long real assets + long a put below spot price + short a call above spot price) and 'Bear Spreads' (long a K2 price put + short a K1 price put, K2>K1). Kinahan (2016) indicated these 2 strategies will stop the unlimited costs . Lastly, CAO should pay more attention to be a risk controller instead of a risk transformer. The company's risk culture should be adjusted immediately because it is too risky for earning capitals without comprehensive considerations.

\section{Fuel Hedging at JetBlue Airways}

\subsection{JetBlue Airways' Fuel Price Management}

Jet Blue should hedge fuel price. Matos (2017) stated the purchase of jet fuel represents nearly $40 \%$ of the total operating expenses. It took a large amount of capitals for Jet Blue, and it will be uncontrollable for the costs if it ignored to hedge. To avoid these risks from fuel's price fluctuations, relating companies used contracts providing the firm with cash flows offset its losses from price changes (Berk \& DeMarzo, 2011).

A normal way for facing jet fuel's increase is to hedge with strategies. Currently, JetBlue hedged $45.71 \%$. As shown in scenario test , it will get 6281.7 million without hedge (5501 million with WTI hedge and 5390 million with Brent Hedge). It can save a lot if it hedge. According to a Bloomberg report (2012), JetBlue main competitors are Alaska Air Group Inc. (50\% hedge), Delta Air Lines Inc. ( $40 \%$ hedge), American Airlines ( $52 \%$ hedge), Hawaiian Airlines ( $56 \%$ hedge), United Continental Holdings Inc. (56\%),Southwest Airlines Co. (hedged). US Airways Group Inc did not hedge, which was the only one. JetBlue was not good enough on hedging but has already saved a lot of capitals.

The other 2 approaches which were to increase ticket prices or eliminate less profitable routes. However, JetBlue did not choose these 2 items like the majority of other airline companies. The reason for this phenomenon was it was hard for evaluate how terrible if they made this kind of choose, and the research would be dramatically expensive with a long time.

\subsection{JetBlue Airways' Costs Hedging}

JetBlue should continue hedging fuel prices but need to decrease the total hedging percentage. It selected heating oil instead of Jet Fuel and the result was JetBlue hedged up to $67 \%$ in 2007 before 2018 and it just hedged $9 \%$ when fuel price went back down in 2009 . The oil price was calculated with a main tendency by the past data, the cost per gallon was around \$3.2, and Jacobs (2012) pointed the jet fuel's price would maintain in a similar level like in 2011 . Hence, the price would still around $\$ 3.2$ which indicated JetBlue could save the cost if it followed the $45.71 \%$ of hedging ratio or made it lower. The reason of lowering the hedging ratio was for satisfying its attitude in exhibit 3. And it tried to maintain the proportion of jet fuel costs in its operating expenses (Exhibit 2' Panel A). lastly, it still could use this strategy for avoid the negative influence from fuel price increases in the future.

\subsection{Cross Hedging's Explanation}

Cross hedging means if there are no same commodity products for hedging in the futures market, the commodity with the 
closest relationship to the spot price (tendency) is used for hedging the value. These 2 items' correlation is very important because if the tendency is perfectly same, the hedging strategy could be perfect as well.

Brent became the most suitable benchmark. As shown in the report, WTI was no more suitable benchmark for the fuel price if it was compared with Brent and heating oil. Brent oil was moving the better together with the oil, but heating oil prices were the closest to the jet fuel prices. Moreover, the Brent price premium to WTI narrowed because the transportation constraints began to ease.

The exhibit 7 showed that Brent had the highest monthly trading volume of contracts in the ICE Europe Futures (Brent had 12454684 contracts and Heating oil had just 77063 contracts). It is important to realise cross hedging's contact's liquidity. Although, heating oil's correlation with fuel was 0.99 by using correlation formular with provided data from 2007 to 2011, which nearly was totally equal to 1 , but its liquidity problem was serious. And Brent's data was 0.97 which was greater than 0.96 for WTI's in 2011 . So, Brent was the most suitable benchmark compared with the other 2 items.

Secondly, the tracking error also can demonstrate which one was the most suitable benchmark, which can assist the former result. The tracking error for Brent-Jet Fuel was 0.15 and WTI-Jet Fuel was 0.23, which meant Brent benchmark was more accurate for tracking the fuel price from 2007 to 2011.

Lastly, in the appendix 5, this graph showed that the main tendency with profits and losses using known data. The tendency from 2007 to 2011, WTI and Brent was nearly same. However, Brent changed its trend following with Jet fuel from 2011, but WTI went far away from these 2 lines.

\subsection{Alternative Risk Management Techniques}

The first technique is to set a bull spread strategy for controlling the cost if the price will go up. This strategy was combined with 2 calls with different strike prices. The specific strategy was to long a call at $\mathrm{K} 1$ and short a call at $\mathrm{K} 2$ (K2>K1). It just earns the benefits if the price goes up. This strategy would be very effective if the company's anticipation is correctly right, which could offset the market risk (fuel price fluctuation risk). Sometimes, it will be also very expensive comparing other put and call strategy because the tendency is not opposite at first.

The second one JetBlue could use is to buy business expense insurance. The reason was fuel's cost accounted $40 \%$ as discussed previously, which was easy to change the operating cost expense due to fuel prices movement. This insurance could provide to reimburse up to $100 \%$ of ongoing and fixed costs. JetBlue could use the history's data for getting an average cost if the hedging strategy was not effective.

Finally, JetBlue can also pay attention to other market risks and use interest rate swaps and exchange rate swaps. Moreover, they can use ERM procession for consolidate the foundation of risk management with relating financial monitoring data. These methods could prevent from normal operating faults in a company. Some other risk types could also be managed by ERM procession because it provides a comprehensive structure for controlling the risk.

\subsection{Risks Analysing}

JetBlue had the protection against market risk likes jet fuel's prices fluctuation. It could avoid large movements in operating cost due to the fuel price accounted $40 \%$ in the total cost. However, it was made by cross hedging with Brent, which still could not be totally hedged with the basic risk (correlation risk).

Although JetBlue used futures, there remained a certain credit risk. Its risk was lower than forward's credit risk, but it still had. For instance, some financial institutions would choose to default on purpose with their strategies as a counterparty due to the systemic risk. And then, JetBlue would lose all the potential benefits.

Lastly, JetBlue was facing other kinds of risk in a market like interest rate risks, foreign exchange risk, inflation risk, operational risk, reputational risk and etc.

\section{References}

[1]Arnold, Wayne. (2005). Five Arrested in Collapse of China Aviation Oil in 2004. (Business/Financial Desk). The New York Times, p. C5.

[2]Berk, J., \& DeMarzo, P. (2011). Corporate finance. Harlow: Pearson international.Bloomberg. (, 2011). Jet Fuel Hedging Positions for US, Canadian Airlines.

[3]Jacobs, K. (2012). Narrowing WTI/Brent Spread Could Aid US Airlines. Reuters.

[4]Kinahan, J. (2016). Essential option strategies: Understanding the market and avoiding common pitfalls.

[5]Mure Dickie. (2004). CAO chief to be questioned in Singapore TRADING LOSSES: Financial Times, p. 34.

[6]Matos, P. (2013). 2012 Fuel hedging at JetBlue airways. Virginia: Darden business publishing.

[7]Prystay, Cris. (2005). CAO Singapore executives are arrested in trading case. (Company Profile). The Wall Street Journal Eastern Edition, p. A5. 